\title{
Influence of vehicle unsprung-mass on dynamic wheel load
}

\author{
M. Miwa ${ }^{1}$, Y. Kawasaki ${ }^{1} \&$ A. Yoshimura ${ }^{2}$ \\ ${ }^{I}$ Technology Research and Development Department (KOMAKI), \\ General Technology Division, \\ Central Japan Railway Company (JR Central), Japan \\ ${ }^{2}$ School of Computer Science, Tokyo University of Technology, Japan
}

\begin{abstract}
Dynamic wheel load variation is one of the major causes of railway track deterioration and ground vibration. Lightening of vehicle unsprung-mass is more effective on reducing dynamic wheel load than that of sprung or intermediatemass. In this paper, we estimate and discuss this effect by combining the following three methods; (1) field tests and measurements with a special equipped train, (2) an experimental method with a unique test facility and real track, and (3) a computer simulation which can calculate dynamic interaction between vehicle and track.
\end{abstract}

Keywords: vehicle-track interaction, computer simulation, test facility, field measurement, dynamic wheel load, unsprung-mass.

\section{Introduction}

The vehicles for Tokaido Shinkansen trainsets replaced lightweight ones in the period 1992 to 2004 for the purpose of maximum operation speed up from $220 \mathrm{~km} / \mathrm{h}$ to $270 \mathrm{~km} / \mathrm{h}$. The axle load of the vehicles was reduced by about $29 \%$, which contributed to preventing an increase in track maintenance and/or ground vibration. However, at that time, we did not have a clear idea of which weight among the unsprung, intermediate and sprung-mass in a vehicle should be reduced. Through our studies since then, it has become clear that the unsprungmass effects most significantly the dynamic wheel load variation, which may deteriorate railway tracks. Three methods, field measurement with the test train, experiments in a laboratory with a large scale test facility and computer simulation of vehicle-track dynamic interaction, are used for these discussions. 


\section{Experimental rolling stock 300X}

JR Central launched the 300X Shinkansen Project in 1990 with the aim of developing the technology for a better and more advanced high speed railway system. We began test runs with experimental rolling stock "300X" in 1995 [1]. As a typical example of our experiments, we lightened the unsprung-mass in three cars in a six-car test vehicle. The lightened unsprung-mass par wheelset was $1.5 \mathrm{t}\left(1 \mathrm{t}=10^{3} \mathrm{~kg}\right)$, while the heavier one was $2.1 \mathrm{t}$. The power spectrum density (PSD) of dynamic wheel load measured at vehicle traveling speed of $270 \mathrm{~km} / \mathrm{h}$ and the PSD of vertical track irregularity are shown in Figure 1 [2].

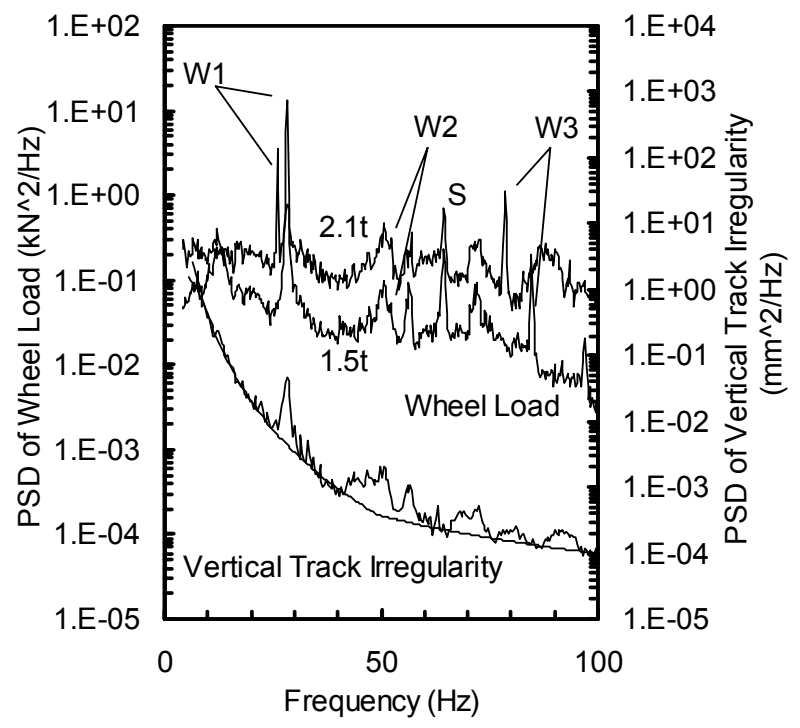

Figure 1: PSD of wheel load and vertical track irregularity.

In Figure 1, some peaks of the wheel load PSD are attributed to following factors,

W1: Rotation-vibration of the wheel

W2, W3: Second and third harmonic of W1

$\mathrm{S}$ : Excitation by sleeper spacing (second harmonic).

The peaks of the vertical track irregularity (ex. around $30 \mathrm{~Hz}, 40-50 \mathrm{~Hz}$ and etc) are attributed to rail surface roughness stamped during production process by rollers of different diameter. Note that in Figure 1, the frequency of wheel load variation is related to that of vertical track irregularity (rail surface roughness). Also note that, those peaks of the wheel load PSD are irrelevant to resonance phenomena which are related to the difference of unsprung-mass. Therefore, in the following discussion, we ignore them.

As shown in Figure 1, lightening of unsprung-mass is effective in significant decrease in dynamic wheel load over wide frequency range. 


\section{Test facility TRADYS}

The full view of the test facility, Track and Structural Dynamics Simulator (TRADYS) [2, 3], is shown in Figure 2. The leftmost axle in Figure 2 is replaced with the vibration exciter. A pair of hydraulic actuators and dead-weight which are equivalent to the unsprung-mass of the vehicle are set here substituting for the original axle. The unsprung-mass is changeable from 1.4 to $2.3 \mathrm{t}$ while its value of the latest Shinkansen is approximately 1.8t. Actuators give relative displacement between rails and wheels (unsprung-mass) forcibly at the fixed point. The displacement given by the actuators represents track irregularities, and therefore, the excitation force is generated as a result of vehicle-track interaction based on a cause-and-effect relationship (see Figure 3). The excitation force is considered to equivalently correspond to the one due to a moving vehicle on a track irregularity.

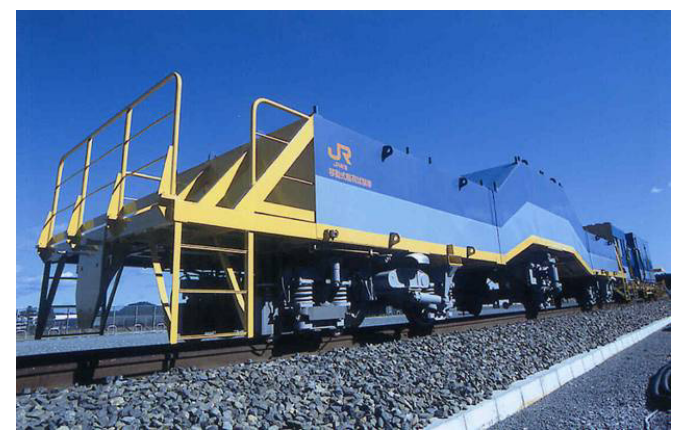

Figure 2: $\quad$ Track and structural dynamics simulator, TRADYS test facility.

\section{Computer simulation}

Figure 3 shows the mathematical simulation model of vehicle-track interaction. The vehicle model consists of a rigid carbody, a rigid bogie and a rigid wheel. The track consists of a single rail supported discretely by sleepers. The rail pad spring and ballast spring are considered to be one-dimensional linear elements. The ballast is assumed to consist of several layers (usually three layers) having each different effective mass. The roadbed is fixed to a ground.

The equations of motion of the vehicle model can be written as

$$
\boldsymbol{M}_{V} \ddot{\boldsymbol{u}}_{V}(t)+\boldsymbol{C}_{V} \dot{\boldsymbol{u}}_{V}(t)+\boldsymbol{K}_{V} \boldsymbol{u}_{V}(t)=-P_{d y n}(t)\left(\begin{array}{l}
0 \\
0 \\
1
\end{array}\right)
$$

where $\boldsymbol{u}_{V}(t)$ is the displacement vector of the vehicle model. $\boldsymbol{M}_{V}, \boldsymbol{C}_{V}, \boldsymbol{K}_{V}$ are the mass, damping and stiffness matrices of a vehicle, respectively. $P_{d y n}(t)$ is external dynamic force acting between a rail and a wheel due to an excitation by 
track irregularity in the case of the real vehicle, or by the forced relative displacement by actuator in the case of TRADYS.

We focus on the vibration with predominant components in the frequency range from $0 \mathrm{~Hz}$ to $100 \mathrm{~Hz}$ caused by the vehicles running on tracks on the ground surface, so the rail is modeled as a simple Bernoulli-Euler beam. In the finite element analysis the rail beam is divided into $\mathrm{N}$ elements $(\mathrm{N}+1$ nodes $)$, as shown in Figure 3.

The equations of motion of the track model are obtained as follows.

$$
\boldsymbol{M}_{R} \ddot{\boldsymbol{u}}_{R}(t)+\boldsymbol{C}_{R} \dot{\boldsymbol{u}}_{R}(t)+\boldsymbol{K}_{R} \boldsymbol{u}_{R}(t)=P_{d y n}(t)\left(\begin{array}{l}
\boldsymbol{a} \\
0
\end{array}\right)
$$

where $\boldsymbol{M}_{R}, \boldsymbol{C}_{R}, \boldsymbol{K}_{R}$ are the mass, damping and stiffness matrices of the track model respectively. $\boldsymbol{a}$ is a vector corresponding to $x_{w}$ which represents the position of a wheel on a rail.

Then the constraint on the vehicle-track motion can be written as the following algebraic equation.

$$
u\left(x_{w}, t\right)+r(t)=y_{w}(t)
$$

where $y_{w}(t)$ is the vertical displacement of a wheel and $u\left(x_{w}, t\right)$ is the vertical displacement of the rail at the exciting position. $r(t)$ is track irregularity or the forced relative displacement by actuator.

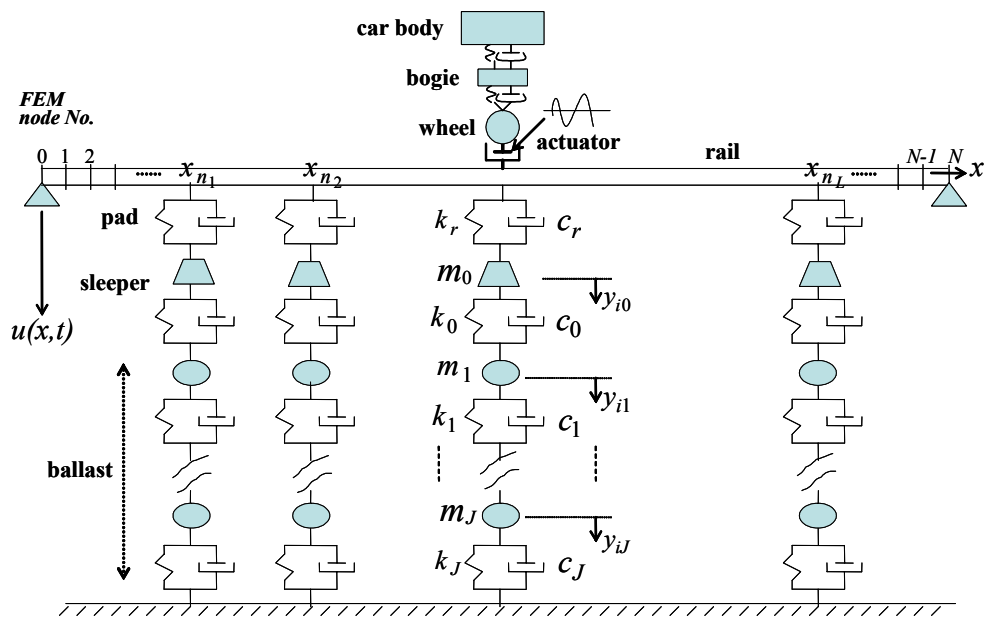

Figure 3: Mathematical simulation model of vehicle-track interaction.

We have obtained the system represented by the two differential eqns (1), (2) and one algebraic constraint eqn (3) for the mathematical simulation model. This is a differential-algebraic equation, DAE. However, it is well known that it is sometimes difficult to solve the DAE directly and to obtain a numerical stable solution. Numerical methods for its solution were described in [3]. 


\section{Examples and discussions}

\subsection{Railway track under consideration}

In the Tokaido Shinkansen, track irregularities are generally maintained all along the line approximately once a year by using a tamping machine, which is called a periodical repair system. However, additional hand-held tamping is needed at some places where the growth of track irregularity is rapid. In such places, not only the maintenance cost increases, but also the train delay may be rarely caused by unpredictably rapid growth of track irregularity. We consider such a weak track as an example in the following.

PSD of vertical acceleration measured on various roadbeds which vehicles are passing near the point at the speed of about $270 \mathrm{~km} / \mathrm{h}$ are shown in Figure 4 . These values are normalized so that the overall values are equal to $1\left(\mathrm{~m} / \mathrm{sec}^{2}\right)^{2}$. The bold line shows average value of six weak tracks as mentioned above. The thin line shows that of six general ones. Dominant frequencies of the weak track are around $20 \mathrm{~Hz}, 10 \mathrm{~Hz}$ and $30 \mathrm{~Hz}$. Before normalization, the value of $30 \mathrm{~Hz}$ of the weak track is larger than that of general one. Therefore, we assume that the frequency range of vertical acceleration of roadbed which affects very rapid growth of track deterioration is lower than about $35 \mathrm{~Hz}$. Then, we focus on dynamic wheel load of lower than $35 \mathrm{~Hz}$ in the following discussions.

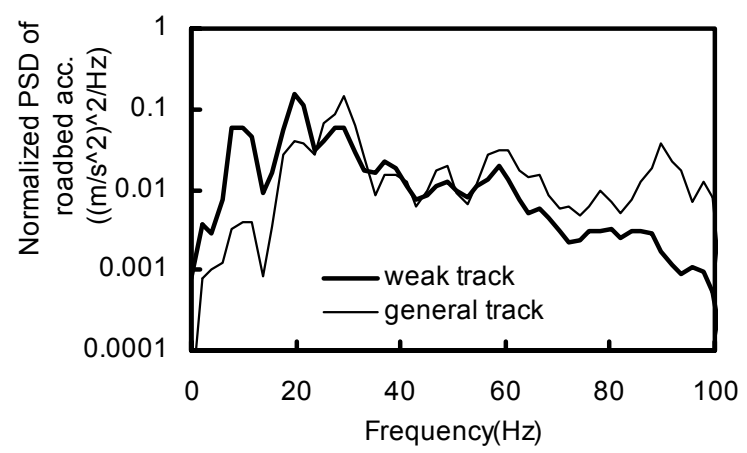

Figure 4: Frequency characteristics of roadbed acceleration of weak/general track.

\subsection{Effect of unsprung-mass (1); field measurement and computer simulation}

As described in Figure 1, it can be said as the field test result that lightening of unsprung-mass is effective in significant decrease in dynamic wheel load over wide frequency range.

Here, we analyze these phenomena with the computer simulation at the fixed point. Parameters of the track model are shown in Table 1. Where the values of (4) stiffness and (5) damping coefficient of rail pad are those of aging degradation under the real use environment. The Parameters from (8) to (18), 
which are not identified enough, are quoted from [4]. Track irregularity data is generated as white noise which PSD is similar in frequency characteristic to that in Figure 1, eliminating the peaks attributed to rail manufacturing process. Values of unsprung-mass are 1.5, 1.8 and 2.1t.

Table 1: $\quad$ Parameters of track model for operational line.

\begin{tabular}{|c|l|c|}
\hline 1 & Rail type & JIS60kg \\
\hline 2 & Unit mass of rail $(\mathrm{kg} / \mathrm{m})$ & 60.8 \\
\hline 3 & Bending rigidity of rail $\left(\mathrm{N} \cdot \mathrm{m}^{2}\right)$ & $6.34 \times 10^{6}$ \\
\hline 4 & Stiffness of rail pad $(\mathrm{N} / \mathrm{m})$ & $160 \times 10^{6}$ \\
\hline 5 & Damping coefficient of rail pad $(\mathrm{N} \cdot \mathrm{s} / \mathrm{m})$ & $400 \times 10^{3}$ \\
\hline 6 & Sleeper spacing $(\mathrm{m})$ & 0.6 \\
\hline 7 & Equivalent mass of sleeper $(\mathrm{kg})$ & 129 \\
\hline 8 & Stiffness of sleeper support $(\mathrm{N} / \mathrm{m})$ & $1.78 \times 10^{9}$ \\
\hline 9 & Damping coefficient of sleeper support $(\mathrm{N} \cdot \mathrm{s} / \mathrm{m})$ & $98.0 \times 10^{3}$ \\
\hline 10 & Equivalent mass of upper ballast layer $(\mathrm{kg})$ & 52.5 \\
\hline 11 & Stiffness of upper ballast layer support $(\mathrm{N} / \mathrm{m})$ & $0.89 \times 10^{9}$ \\
\hline 12 & Damping coefficient of upper ballast layer support $(\mathrm{N} \cdot \mathrm{s} / \mathrm{m})$ & $980 \times 10^{3}$ \\
\hline 13 & Equivalent mass of middle ballast layer $(\mathrm{kg})$ & 52.5 \\
\hline 14 & Stiffness of middle ballast layer support $(\mathrm{N} / \mathrm{m})$ & $0.81 \times 10^{9}$ \\
\hline 15 & Damping coefficient of middle ballast layer support $(\mathrm{N} \cdot \mathrm{s} / \mathrm{m})$ & $980 \times 10^{3}$ \\
\hline 16 & Equivalent mass of lower ballast layer $(\mathrm{kg})$ & 90.3 \\
\hline 17 & Stiffness of lower ballast layer support $(\mathrm{N} / \mathrm{m})$ & $2.50 \times 10^{9}$ \\
\hline 18 & Damping coefficient of lower ballast layer support $(\mathrm{N} \cdot \mathrm{s} / \mathrm{m})$ & $980 \times 10^{3}$ \\
\hline 19 & Roadbed & $\mathrm{Rigid}$ \\
\hline
\end{tabular}

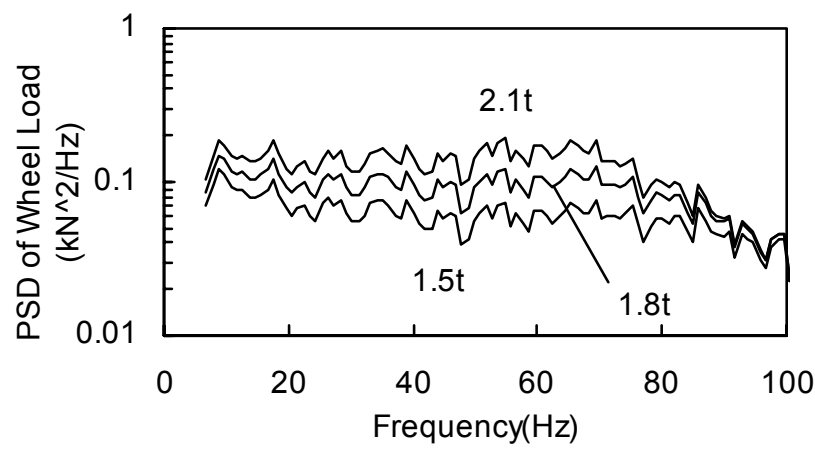

Figure 5: Computational results as similar conditions as Figure 1.

One of the results of numerical simulation is shown in Figure 5. Where, the simulation is not executed in frequency-domain but in time-domain. The effect in reducing wheel load variation by lightening unsprung-mass is clearly shown in Figure 5 as well as Figure 1. The PSD of wheel load shown in Figure 1 and Figure 5 relatively correspond with each other in lower than $80 \mathrm{~Hz}$, except for the 
peaks ignored. As described in the section 5.1, accuracy of simulation in frequency of higher than $80 \mathrm{~Hz}$ is unnecessary here. Therefore, the accuracy of this simulation required for this case is satisfactory.

\subsection{Effect of unsprung-mass (2); TRADYS test facility and computer simulation}

The TRADYS (Figure 2) and test track are installed in the KOMAKI R\&D Complex of JR Central. Test results of one of the standard track of the Tokaido Shinkansen shown in Table 2 are described as an example. Where, abbreviated parameters are the same as those of Table 1, whereas (4) stiffness and (5) damping coefficient of rail pad are values of brand-new one. Ballast mat is laid between lower ballast layer and rigid roadbed. Track irregularity data is the same as the case of Figure 5.

Experimental results obtained by TRADYS are shown in Figure 6. Calculated results of the computer simulation are shown in Figure 7. These two results have a lot in common as follows.

- There are gently sloping convex shapes around $35 \mathrm{~Hz}$, because of resonance phenomena which are originated by the ballast mat addition.

- The resonance frequencies are changed slightly depending on their unsprung-mass.

- The lighter the unsprung-mass are, the lower the wheel load variations are, in the lower frequency than about $40 \mathrm{~Hz}$.

Table 2: $\quad$ Parameters of track model for TRADYS test facility.

\begin{tabular}{|c|l|c|}
\hline 4 & Stiffness of rail pad $(\mathrm{N} / \mathrm{m})$ & $50.0 \times 10^{6}$ \\
\hline 5 & Damping coefficient of rail pad $(\mathrm{N} \cdot \mathrm{s} / \mathrm{m})$ & $25.0 \times 10^{3}$ \\
\hline 17 & Stiffness of ballast mat $(\mathrm{N} / \mathrm{m})$ & $50.0 \times 10^{6}$ \\
\hline 18 & Damping coefficient of ballast mat $(\mathrm{N} \cdot \mathrm{s} / \mathrm{m})$ & $49.0 \times 10^{3}$ \\
\hline
\end{tabular}

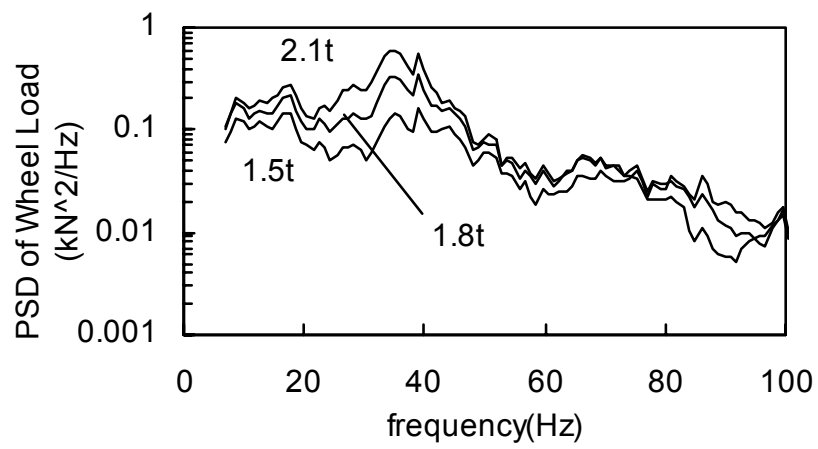

Figure 6: Effect of unsprung-mass in wheel load variation (experimental). 


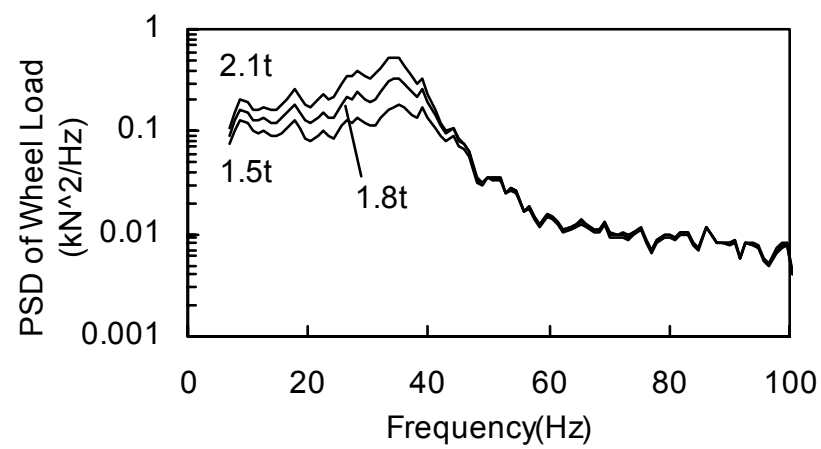

Figure 7: $\quad$ Effect of unsprung-mass in wheel load variation (computational).

However, there are minor differences in the higher frequency by about $50 \mathrm{~Hz}$. This reason is assumed that the amplitudes of track irregularity are much smaller than the guaranteed resolution of displacement sensors for actuator control of TRADYS test facility. As mentioned before, note that, accuracy of such higher frequency is not necessary for discussions here.

Consequently, we can evaluate that the computer simulation provides enough accuracy, and also, lightening unsprung-mass is effective in reducing dynamic wheel load even on softly supported track.

\subsection{Effect of intermediate-mass}

Intermediate-mass is indicated as "bogie" in Figure 4. Results of numerical simulations in different intermediate-masses are shown in Figure 8. The parameters of intermediate-mass are chosen as $83 \%, 100 \%$ (general value of the latest Shinkansen vehicle) and $117 \%$. These ratios are the same as the abovementioned parameters of unsprung-mass. Track conditions are shown in Table 1. Track irregularity data is the same as that of the case in Figure 5.

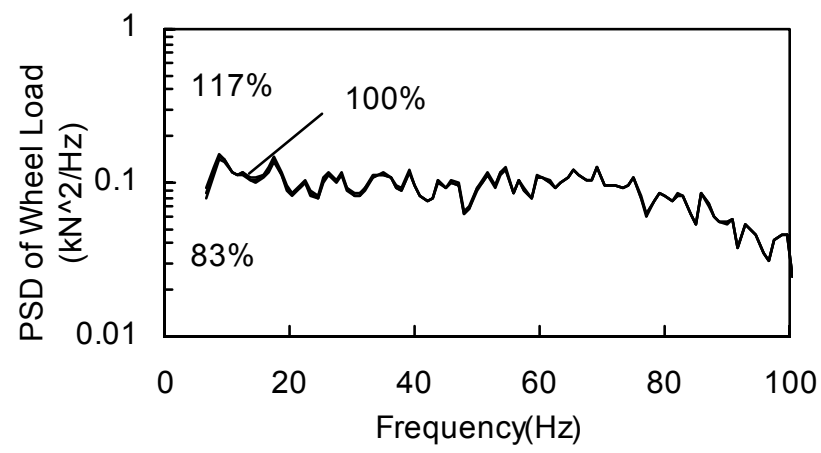

Figure 8: Effect of intermediate-mass in wheel load variation (computational). 
As shown in Figure 8, only a slight difference in wheel load variation is seen while intermediate-mass is changed definitely. Therefore, the effect of intermediate-mass in dynamic wheel load is negligible compared to unsprungmass.

\subsection{Effect of sprung-mass}

Sprung-mass is indicated as "car body" in Figure 4. Based on results of numerical simulations, there is very little difference in wheel load variation while sprung-mass is changed definitely. Its difference is smaller than the case of the intermediate-mass. Therefore, the effect of sprung-mass in dynamic wheel load is negligible as well as intermediate-mass compared to unsprung-mass. Figure of wheel load PSD is not shown due to space limitation.

\subsection{Suppression of dynamic wheel load associated with speed-up}

As described in the introduction, the operational speed of the Tokaido Shinkansen was increased from $220 \mathrm{~km} / \mathrm{h}$ to $270 \mathrm{~km} / \mathrm{h}$. At that time, unsprungmass of vehicle was decreased from $2.3 \mathrm{t}$ to $1.8 \mathrm{t}$. Here, we discuss about the effect of lightening unsprung-mass on suppressing dynamic wheel load associated with speed-up. Results of numerical simulations under vehicle conditions in Table 3 are shown in Figure 9. Track conditions are shown in Table 1, and track irregularity data is the same as that of the case in Figure 5.

Table 3: $\quad$ Vehicle conditions for numerical simulations.

\begin{tabular}{|c|c|c|c|}
\hline & $\begin{array}{c}\text { Speed } \\
(\mathrm{km} / \mathrm{h})\end{array}$ & $\begin{array}{c}\text { Unsprung- } \\
\text { mass }(\mathrm{t})\end{array}$ & Situation \\
\hline A & 220 & \multirow{2}{*}{2.3} & Before speed-up with OLD vehicle \\
\hline $\mathrm{B}$ & \multirow{2}{*}{270} & & After speed-up with OLD vehicle (virtual example) \\
\hline $\mathrm{C}$ & & 1.8 & After speed-up with NEW vehicle \\
\hline
\end{tabular}

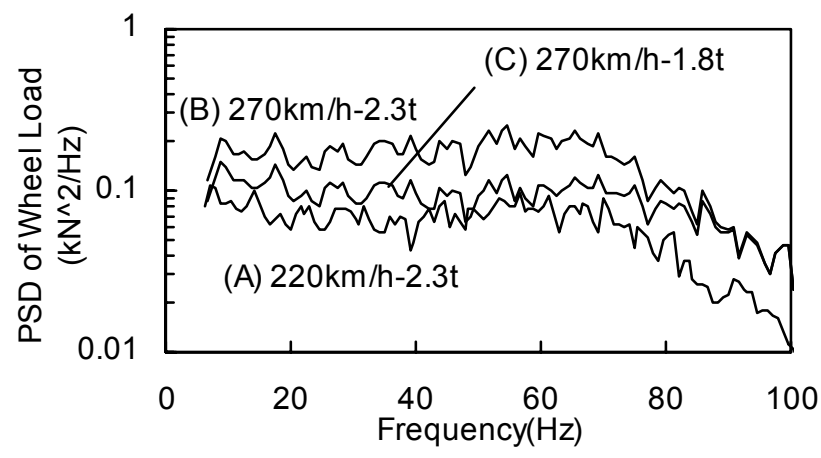

Figure 9: Suppression of dynamic wheel load associated with speed-up by lightening unsprung-mass (computational). 
In Figure 9, if the operational speed was increased without lightening unsprung-mass $(\mathrm{A} \rightarrow \mathrm{B}$ in Table 3 ), PSD of wheel load in the frequency lower than $35 \mathrm{~Hz}$ would increase roughly 2 -fold before speed-up. However, because unsprung-mass was lightened at that time $(\mathrm{A} \rightarrow \mathrm{C}$ in Table 3), increase of the PSD could be prevented roughly 1.3 -fold.

\section{Conclusions}

The accuracy of our computer simulation for vehicle-track dynamic interaction has been confirmed by comparing with field measurements and experiments with large scale test facility. By using these three methods, mainly the computer simulation, the effect of lightening unsprung-mass in reducing dynamic wheel load has been shown specifically. We have verified the decision of JR Central that vehicle unsprung-mass of high-speed rail should have been lighter.

\section{References}

[1] Ishizu, K., et al, The result of the running tests exceeding $400 \mathrm{~km} / \mathrm{h}$ with the Shinkansen experimental train 300X, Proc. World Congress on Railway Research (WCRR) '97, Vol. D, pp. 803-812, 1997.

[2] Miwa, M. \& Nakamura, S., High speed running test and the new testing equipment for wheel/rail dynamic interaction, Proc. of Int. Symposium on Speed-up and Service Technology for Railway and Maglev Systems (STECH’03), JSME, pp. 489-493, 2003.

[3] Miwa, M. \& Yoshimura, A., Study on vertical dynamic vehicle-track interactions using the TRADYS test facility and computer simulation, Computers in Railways X (COMPRAIL2006), pp. 885-894, 2006.

[4] Ishida, M., Miura, S. \& Kono, A., The influence of track stiffness on track dynamic behavior, Quarterly Report of Railway Technical Research Institute, Vol. 38 No. 3, pp. 129-134, 1997. 